\title{
Sexual violence and the Object of Attribution of Responsibility in Georgian Youth
}

\author{
Natalia Mchedlishvili, PhD student \\ Free University of Tbilisi
}

\begin{abstract}
The aim of this study is to answer the question: what do Georgian youth consider as sexual violence and who is responsible for sexual violence in different situations? There was no such academic study on sexual violence in Georgia and it was the issue that had not been researched. Qualitative methods were used as research method: sexual violence case study, in-depth interview and focus group. The specific examples of sexual violence cases had been prepared by the researcher in advance and based on them in-depth interview and focus groups were conducted with Georgian youth. The participants of the research were Georgian students. The study has been conducted in Georgia and includes the two biggest cities Tbilisi and Batumi. The results of the research revealed that the participants consider as sexual violence the following: sexual intercourse using physical force; repetitive unwanted replicas; coercive sexual intercourse; spreading someone else's sexual content photos and videos; The reasons for considering a particular case AS sexual violence are: physical force is used; psychological pressure is used; It happens against the will of the partner; The partner did not agree or was in a situation where she/he could not give consent. They attribute responsibility to the abusive person, but in some cases they distribute responsibility to victims too. The Research is fully funded by Shota Rustaveli National Science Foundation of Georgia.
\end{abstract}

Keywords: attributions of responsibility; Georgia; qualitative methods; sexual violence; youth. 